\title{
La formalización escritural
}

\author{
Amancio Chävez Reyes \\ Departamento Académico de Lingüistica
}

\section{Introduccion}

Todas las lenguas del mundo surgieron como formas exclusivamente acústicas (u orales) y de la manera más natural e inconsciente, tal cual se registra en la historia de la humanidad. A partir de ésta han venido tomando un modelo gráfico y asi han podido responder, cada vez con mayor eficiencia, a las exigencias sociales, que a su turno también fueron más complejas. Las formas orales o auditivas se transfieren a modelos visuales. Mediante este proceso los mensajes se convierten en material de lectura. La lengua, en este caso, es plenamente de carácter cultural, audiovisualizada.

La audiovisualización de las lenguas es un proceso sociolingüistico que responde a la necesidad de transferencia del cúmulo de culturas, de una generación precedente a las posteriores, a la vez que transfiere a grupos humanos espacialmente distanciados. Esta es fa consecuericia de una lengua formalizada, y ésta es posible sólo mediantéla asunción de lapprátécéscritural. Sin embargo no fue una realización uniforme, por un lado, ni alcanzó a responder con la misma efervescencia en todas las culturas y grupos, por otro lado. Muchas comunidades lingüisticas no tuvieron necesidad. Los grupos que transfierieron su forma hablada a la escritura, por cierto que alcanzaron las mejores posibilidades de realización sociocultural e incluso económica, a la vez que ella asistió al encumbramiento intelectual de los usuarios más cultivados. A diferencia de éstas, las que permanecieron en estado natural (agrafia) fueron cada vez impedidas de acceder a ser el receptáculo y transmisora de modelos de cultura formal.

La escritura significó, para el hombre, una posibilidad de incursión en las esferas de abstracción. El ágrafo ha sido rezagado por la historia, forma parte de una sociedad primaria en la que la comunicación interpersonal se procesa con la presencia fisica de los interlocutores. 
Dialécticamente, la escritura creó la segmentación de lenguas y grupos humanos que subsisten en relaciones asimétricas constituidas en una lucha de contrarios, sin posibilidad de alcanzar la armonía social. La escritura creó un desequilibrio social y disarmonía interlingüe, no obstante que ésta tiene su propio rol histórico de suma importancia.

\section{2) Oralidad y escritura}

La oralidad y la escritura son los modelos a través de los cuales se materializan las lenguas como fenómeno sensorial. Las formas escritas obedecen al avance cultural de los usuarios. La oralidad refleja la naturalidad y la espontaneidad de la lengua; la forma escrita, en cambio, es convencional, cultivada y visual.

Las formas oral y escrita, entre sí, no necesariamente son correspondencias exactas. La escritura podría resultar desfasada de su modelo oral, tal cual sucede en las lenguas como japonés, chino, ruso, que adoptan escrituras muy diferentes a sus formas orales. Se advierte al respecto, que el modelo fonológico es lo más recomendable para diseñar el patrón gráfico, dado que es lo más económico, convencional y racional, no obstante su naturaleza abstracta y arbitraria.

Cualquier lengua del mundo puede ser transferida a la forma escrita, para esto es necesario que el grupo usuario tome interés al respecto y pueda diseñar un patrón alfabético. Es lasícóme empezarōn a ser escritas todas las lenguas, que actualmente gozan de tradición escrita. Es necesario advertir que las lenguas tienen su propios modelos. Al respecto debemos incidir que cada lengua tiene sus propios patrones o modelos fonológicos, diseñados sobre la base de su propio material auditivo o fonético, pre-existentes en su oralidad correspondiente y la escritura debe estar basada en esta particularidad, no tiene que imitar a ninguna otra lengua como la que se pretendió implantar las vocales del castellano para instituir el alfabeto quechua. Las lenguas, deben tener su modelo propio, en esto consiste su autonomia y personalidad histórica y estructural, que cada lengua ha alcanzado a través de su continuidad práctica. En consecuencia, la formulación de un patrón de escritura no es, ni puede ser un invento, ni de aficionados, ni de especialistas, es la transcripción de la forma auditiva que proporcionan los sonidos articulados, si ésta es fonográfica. Las coincidencias entre una y otra lengua, en todo caso, son apenas implicancias de grados de semejanzas que puede existir entre los sistemas que a lo mejor podrían estar emparentadas, por razones históricas o de cercania espacial y constante interrelación, o por razones filogenéticas. 
La historia de la humanidad en sus fases iniciales alcanzó grandes logros civilizatorios mediante el uso exclusivo del lenguaje en su modalidad oral, aunque este hecho orientó el desarrollo humano en términos eminentemente materiales, concibió su mundo y sus posibilidades de vida con criterios objetivistas e inmediatistas. He ahi el caso de la educación practicada en las grandes culturas como la Inca y las Pre-Incas, entre otras, por sefialar lo nuestro. Para los hombres de su tiempo les fue suficiente la expresión oral, y puede decirse, más bien, que fue un modelo uniforme y nivelador, con las mismas posibilidades para todos, sin más parámetros que su condición humana.

En el lenguaje, instituido como modelo social, expresa el grupo social su modo de producción económica. El inventario lexical, en cada lengua, compila predominantemente el quehacer socioeconómico del grupo usuario. Teniendo en cuenta esto es posible que uno y otros grupos humanos tuvieron en su realización histórica, uno u otro modo de producción.

Así por ejemplo, un pueblo o cultura podría definirse, en atención a su inventario lexical predominante como que fue industrial, agricultor, ceramista, pescador, cazador, etc. Teniendo en cuenta este criterio se la caracteriza por ejemplo a la cultura Inca como Agricola.

El quechua, lengua inca, o más propiamente prehispánica, registra en su inventario lexical abundante cantidad de términos referidos al cultivo de la tierra como testimonio que evidencia el carácter agricola de strcultura. La cosmogonía inca, con justificada razón y comológica explicación de su concepción del mundo idealizó la tierra como su deidad progenitora. He ahi el porqué de la Pachamama y las festividades dedicadas a las diferentes etapas de la agricultura, desde la siembra hasta la cosecha. Este hecho lo demuestra en los términos referidos a los objetos de cultivo como el maiz (hara, sara, o ara) y papa (o akshu), que fueron bases temáticas que sirvieron como indicadores de un gran vocabulario, que sólo el hombre compenetrado como miembro activo de esta cultura, como integrante nativo lo conoce y lo dominá, a la vez que lo usa con familiaridad y competencia natural porque forma parte de su existencia. Sara o akshu presentan un léxico.

El quechua es una lengua oral, que a ciencia cierta no alcanzó la escritura de carácter, ni fonética, ni fonológica. En todo caso, las posibles manifestaciones escriturales no fueron alfabéticas, aunque podríamos asegurar que el modelo alfabético no es lo único que indica la realización gráfica de las lenguas en el mundo. 
Lo sustantivo no es que el quechua haya o no tenido escritura a la llegada de los invasores, lo preocupante es que la subsistencia colateral y pasiva durante estos últimos cinco siglos han sido de constante resistencia. Afincado en su idiosincrasia el hombre andino ha formado su pensamiento, su dignidad y su expresión etnológica de profundo arraigo telúrico y ésta es la justificación para los andinos que entendieron el campo (el cultivo de la tierra) como su posibilidad de realización y desarrollo.

La presencia del castellano en el Perú significó la periferiación y secularización del quechua en su función sociocultural, que fue marginado en su posibilidad de formalización. Asimismo, la constante persecución e inquisición antiquechua hizo que el sistema imperante, implantado después de la conquista, incidiera en la actitud de los hablantes que se polarizaron entre la lealtad y deslealtad lingüistica. En consecuencia, no es gratuita la devaluación del quechua por parte de la misma gente andina, que ha sufrido la contaminación alienante del castellano hablante, es resultado de la permanente y sistemática mentalización perpetrada incluso por la educación.

Las lenguas que no tienen una tradición escrita pueden adoptar un modelo a partir de la transcripción de los sonidos que proporcionan los usuarios. Todas se realizan fonéticamente: pero no todas tienen escritura fonológica y ni fonética. Es recomendable, porrazones de funcionalidad y universalización, que las lenguas deben escribirse con este criterio y para que el acceso a ellas no sea tan difícil como la quelpodra ser per ejempleaprender a escribir el griego, el chino o el japonés.

\section{3) Diseño de patrones escriturales}

Todas las lenguas en su etapa de formación, antes de llegar a ser el modo de habla autónoma e independiente, requieren tener sus propios patrones y/o estructuras que garanticen su condición de lengua. Estas estructuras pueden ser el resultado de una desmembración sufrida anteriormente, o más bien, de una confluencia espacial de sistemas. En el primer caso se trata de una escisión a partir de una protolengua o matriz central, $y$ en el segundo caso se produce como una mixturación. Estos casos devienen en divergencias y convergencias linguisticas, respectivamente.

Las estructuras iniciales, en las lenguas nacientes son adaptaciones fonéticas a partir de variantes articulatorias para convertirlos en fonemas propios de 
la lengua que presenta ciertas caracterizaciones alofónicas en su realización. La combinación de fonemas devienen en unidades referenciales o lexicales. Su distribución significa las posibilidades combinatorias de fonemas y la frecuencia y/o productividad de los mismos.

La distribución fonológica se refiere a la serie de condicionamientos entre los diferentes fonemas de la lengua como norma interna. No todos los fonemas tienen distribución irrestricta ni las mismas frecuencias. Asi por ejemplo, no pueden combinar entre sí, como unidades de articulación intrasilábica, dos fonemas que presentan los mismos rasgos físiológicos. No hay combinaciones entre sonidos hormogánicas, éstas siempre son heterorgánicas. Es decir, no pueden formar grupos consonánticos por ejemplo dos bilabiales como $/ \mathrm{m} / \mathrm{b} / \mathrm{p} /$. No es posible la combinación /pm,pb,bm,mp,bp, mb/ como formantes de una misma sílaba en la misma posición, una pre o pos nuclear, y por tanto como unidad de articulación. Las posibilidades combinatorias entre los fonemas resultan inherentes a cada lengua. Unas lenguas tienen combinaciones fonológicas intrasilábicas más complejas que otras. Por ejemplo, el castellano presenta combinaciones fonológicas más complejas que el quechua y luego el número de combinaciones en castellano-llega a 18 y en quechua son 4 las posibilidades ((c)v(c)) sin que por ello se entienda como alguna limitación para su producción lexical La abundancia o escasez lexical es reflejo de incidencias extralinguísticas que nada tienen que ver con la estructura y desarrollo internos.

\section{Biblioteca de Letras}

El diseño de patrones estructurales pararuna Jengua significa la convencionalización formal para dotarla de escritura. Se trata de una comunidad usuaria de lengua ágrafa, o, en algunos casos, puede tratarse del cambio de modelo escritural, tal cual podría ser el cambio de una escritura simbólica a otra alfabética. Por ejemplo, esto ocurriría si la actual escritura china cambiara a un sistema fonológico. La escritura es un modelo artificial con que se diseña la graficación de una lengua para su ulterior práctica. La escritura es resultado de un planeamiento lingüístico en el que convergen especialistas, sean o no usuarios. Asimismo, la formulación del patrón escritural obedece a una politica lingüistica oficial. Ni los especialistas, ni los usuarios, ni siquiera las entidades científicas están autorizadas a dotar de escritura a una lengua si no cuenta con la autorización oficial del Estado o de las organizaciones nativas que tienen carácter resolutivo. La escritura no es sólo la práctica, ni puede ser el simple conocimiento de ella. Su punto de partida está en la planificación previa, toda vez que ésta garantiza una práctica uniforme; de lo contrario no tendría ninguna razón de ser. 
Sin embargo, es de advertir que la formulación del cuadro fonológico podría ocasionar alteración o distorsión de la naturaleza fonémica de la lengua. Podrian ocurrir ingerencias de carácter ideológico y/o politico en la formulación de fonemas y crear, incluso, una separación inexplicable entre las formas oral y escrita. Hay quienes subjetivizan y folclorizan y hasta fetichizan la escritura. Asi por ejemplo, se pretendia escribir el quechua más o menos supeditada a la forma castellana. Esto no es advertir la diferencia estructural entre ellas, por considerarlas lenguas en contacto "armónico" o lenguas "emparentadas"1. Los patrones escriturales deben estar libres de todo subjetivismo y dependencia.

\section{4) La escritura como superestructura}

Toda lengua en su modalidad oral se inicia como una necesidad primigenia en las condiciones más naturales e incluso inconsciente, sin que el usuario la advierta, ni de sus complejidades estructurales, ni de su naturaleza sistemática. El hombre logra utilizarla para proyectarse a los otros hombres de su entorno sin más deseo que el de su convivencia social. La lengua da cobertura, inicialmente, a los deseos puramente naturales. Es asi cómo el niño aprende a pedir comida, agua, o que le asistan en sus requerimientos fisiológicos mediante el descubrimiento y uso de códigọs puramente denotativos a los que secuencial y progresivamente le atribuirá cargas emocionales; repite simplemente las formas que escucha en su rededor o incluso en la naturaleza, tales como las reproducciones de ruidos o sonidos para cuyotefectođađoptąsus órganos fisiológicos.

\section{"Jorge Puccinelli Converso»}

La forma oral del lenguaje es como una estructura de base que ayuda al hombre a alcanzar niveles de su realización social e individual. Las sociedades primarias se caracterizan por ser usuarias de esta clase de lenguaje en las condiciones de hablante/oyente. Hasta este momento el hombre es apenas un usuario empírico y puede asegurarse que a este nivel todos los hablantes y/u oyentes registran exactamente las mismas competencias aunque a nivel de performance unos tendrán más habilidad para mostrarse más locuaces que otros, que en términos socioculturales no existen diferencias entre los ágrafos. La escritura, con todas sus bondades marca la diferencia entre los usuarios, entre los que escriben y los que escriben bien.

1 El contacto quechua-castellano, en términos sociales han sido de permanente persecución: es indudable pensar en la posible armonia entre sus usuarios, en las mismas condiciones los aspectos estructurales son de penetración, que crea estados de alteración funcional y luego el debilitamiento estructural. 
No obstante que la oralidad representa la simbolización lingulística del universo conocido por el hombre, este nivel de lenguaje presenta serias dificultades para la avanzada cultural que se torna cada vez más cientifica y abstracta. El mundo de hoy es, para el hombre, más exigente, más intelectivo, más artificial, a la vez que más moderno y universalizante. He ahí la modernización y la globalización como fenómenos comprometidos con las necesidades del desarrollo humano, amén de sus implicancias ideológico-politicas.

La escritura es una práctica formalizada de una lengua, transferencia a partir de la oralidad, que hace el usuario, escribiente y/o lector, a partir de su asunción audiovisual. Para este hecho las comunidades asumen el uso de un cuadro abstracto y convencional que simboliza los sonidos existentes en su lengua, se instituye el patrón fonológico representado mediante grafias o letras, si la escritura ha de ser alfabética, 0 , mejor, fonográfica.

Entre la oralidad y la escritura no hay una correspondencia materialmente condicionada, las relaciones que se establecen son convencionales, que se transforman en costumbres; esto lo evidencian los diferentes modelos de escritura con que se representan gráficamente las lenguas. Asi por ejemplo, la lengua china es representada mediante símbolos no alfabéticos; en cambio las lenguas indoeuropeas presentan una escritura grafémica. La escritura fonológica viene a ser la más económica, basada en un número finito de grafias; aunque no deja de ser la más arbitraria, se constituye en la alternativa más adecuada, la más cientifica y modema, además de alta funcionalidad.

La condición de hablante/oyente se alcanza como simple proyección del hombre a su entomo, por un proceso adquisitivo; en cambio la de escribiente/ lector se alcanza mediante un proceso de enseñanza-aprendizaje, con la participación activa de un enseñante y un aprendiz. La escritura es una conducta aprendida, volitiva e intelectivamente; ya no es natural ni meramente adquirida como que lo es la forma oral correspondiente. La escritura es artificialmente acufiada y normativamente practicada.

La escritura constituye un modelo superestructural a diferencia de su oralidad, que para este caso la consideramos como la estructura de base por su naturalidad, materialidad y espontaneidad. La escritura es elaborada, aprendida y formalizada e instituida. La escritura, necesariamente, se instituye sobre la base de una forma oral. No hay una escritura que no esté basada en una lengua natural; pero hay lenguas sin escritura. Es más, la escritura en su condición de 
superestructura puede ser regulada periódicamente por la voluntad de sus usuarios o incluso ser sustituida por otros modelos. Asi por ejemplo la escritura simbólica como la que posee la lengua china puede ser reemplazada por un modelo alfabético; en cambio la forma oral constituye la idiosincrasia internalizada, forma la tradición aborigen del usuario y está comprometida con la etnicidad del grupo. Nadie podría olvidar su habla repentinamente, salvo a través de varias generaciones.

La escritura, en su condición de superestructura, es un sistema que se desarrolla dentro de sus cánones estrictamente organizados; el hombre no tiene más que practicarla de acuerdo a criterios establecidos, no son admisibles las informalidades individuales ni grupales como que si se da en la forma oral. Para cada lengua hay un solo modelo de escritura, es una constante homogénea. A esto tienen que llegar quienes aprenden, y no es como la oral, que llega a modelos individuales que incluso está condicionada a circunstancias.

La escritura es superestructura porque obedece a una necesidad superpuesta a la forma oral y responde al deseo de plasmar en ella el quehacer cultural, el pensamiento y la tendencia científico-tecnologica predominante del momento. Es un modelo artificial que no representa con facilidad las sugerencias que presentan los fenómenos a los que simbolizan. Es un modelo acuñado que procura transferir la oralidad sin que exista una relación entre ellas, como que es superestructura su práctica obedece a la concepción convenida de quienes diseñan desde el inicio su posible práctical Obliga â todos asumir el raismo modelo, nadie podría escribir si no es sobre ebmodelo social. Eb hombre tiene libertad para usar su lengua como un hecho articulado; pero nadie está permitido hacerlo gráficamente. Ni siquiera los diferentes niveles culturales o educativos de los que escriben les daría libertad. Sólo a través del tiempo se introducen y admiten algunos cambios, pero que también serán sólo un modelo. En esto consiste la uniformidad estructural y normativa de la lengua como sistema unitario.

\section{5) Normalización de la escritura}

Una vez dotada de escritura, la lengua requiere, para su práctica, de un afianzamiento y realización cada vez más productiva y frecuente. Normalizar una lengua es abstraer una serie de normas existentes en la lengua y que deben ser aprendidas para que ésta tenga un modelo uniforme y sea una práctica unitaria en todas sus realizaciones lecto-escriturales. Los diferentes grados de pausa, 
representados gráficamente mediante los signos de puntuación corroboran también como normas que permiten lograr mejores niveles de entendimiento.

La ortografia se entiende como la correcta representación gráfica, tanto de las palabras como de las oraciones o unidades de comunicación. Luego, puede sustentarse que existen dos niveles ortográficos: una ortografia, de la palabra, y otra, de la oración. Acaso una ortografia lexical de carácter alfabético fonográfico (o fonológico) y otro sintáctico (frasal u oracionál)? Esto mismo nos hace ver que las lenguas tienen un doble aspecto fonético, uno segmental y otro suprasegmental. He ahi las reglas ortograficas que recomiendan el uso de fonemas, la tilde y los signos de puntuación. El uso correcto de estos componentes complementa las diversas funciones de la lengua, las mismas que varian desde la simple referencia denotativa hasta las expresiones de alta subjetividad emocional o incluso subliminal, como que podrian ser las odas o elegias poéticas.

La normalización lexical está en relâción al diseño gráfico, real o artificial, del cuadro fonologico formulado sobre la base de lo persistente en la lengua. Esto significa que los patrones fonéticos no son ningún invento de especialistas o aficionado alguno. La convencionalización se da sobre la base de una realidad que tiene tradición en su oralidad. De esto se tienen las reglas ortográficas y la distribución fonológica, así como también la serie de condicionamientos fonológicos que forman los grapos fónicos en todas las lenguas. En unas resulta, esto, más complejo que en otras.

Las normas indicañ das diferentes màneras de realización de los componentes de la lengua. Éstas, según los niveles constitutivos, pueden ser libres, fijos o mixtos. Por ejemplo en el nivel fonológico la norma es más estricta, de tal manera que uno puede resultar hasta impedido de realizarse en ciertos ambientes. Por ejemplo en quechua no hay grupos, ni vocálicos, ni consonánticos; que en el castellano las bilabiales no suelen ocurrir en final absoluto, o nunca dos consonantes en castellano pueden estar en final de palabra.

Es una norma en el quechua, a nivel de sintagma nominal el hecho de que el adjetivo ocurra antes del hombre y nunca después de éste como que en el castellano sí puede estar antes o después. No obstante esto es necesario advertir que hay casos en que resultan condicionamientos, acaso estilisticos? que limitan la secuencia adjetivo + nombre. P.e., no es costumbre decir chiquito cheque, chiquito nornbre como que son totalmente normales decir cheque chiquito u hombre chiquito o rosa roja y roja rosa. El quechua presenta el SN como 
adj. + nombre.: shumaq warmi, ata aqtsa, waktsa marka o aruq runa. En el casteIlano puede ser flor hermosa o hermosa flor. La FN en esta última es relativamente libre. En quechua hay orden fijo.

Asimismo ocurre a nivel suprasegmental como que es el sistema acentológico. En este aspecto, también cada lengua tiene sus regimenes de comportamiento. Asi por ejemplo el quechua presenta un acento fijo. Esto significa que es posible prever y por tanto no es exigencia tildar las palabras; en cambio en el castellano, que presenta el acento libre es necesario tildar las palabras, de acuerdo a una serie de normas internas que prescriben el uso adecuado. De ahí que su práctica refleja, incluso, la cultura ortográfica del usuario.

En suma, la normalización de la escritura significa la regulación periódica de los patrones de escritura a fin de garantizar la estandarización para mantener la uniformidad escritural y actualizar los patrones escriturales para que no sean totalmente desfasados del modelo oral; tampoco sería lícito pensar que la ortografia y las normas gráficas sean totalmente estáticas, como que si la lengua no variara de un tiempo a otro. Las normas internas de una lengua cualquiera sufren variaciones a partir de sus manifestaciones orales, individuales y sociales, que en su inicio parecieran incluso atentatorias contra lo instituido. Las normas como expresión oral suelen cambiar permanentemente y dan la impresión de una incontrolabilidad. Muchos de estos cambios son totalmente regulares; pero que el usuario, incluso educado, no lo advierte en sus manifestaciones iniciales. La escritura interviene como ün modelo consolidado,cuando los cambios son reconocidos como hechos finalesccinelli Converso»

Las normas son recomendaciones que se tienen en toda lengua y con este objetivo existe por ejemplo en el castellano la Real Academia Española, además de las academias nacionales o filiales. A través de estas entidades se regulan las normas como reconocimiento de formas orales que alcanzan arraigo, especialmente a nivel segmental. En lo que respecta a los signos de puntuación no parece ser de mucha exigencia ni exactamente una homogeneidad. Estos contribuyen más bien al estilo personal de quien escribe. Los préstamos deberían estar sujetos a una constante normalización a fin de mantener la capacidad asimilativa y depuradora de la lengua, toda vez que esto contribuye a su vez a mantener la distribución fonológica de la lengua. 
1) La escritura es una práctica transferida de su correspondiente oralidad y para esto se diseña previamente un patrón fonológico que sirve de base a la graficación. Esta fonografización, como que es en castellano, reconoce el uso de un alfabeto. La escritura contribuye a la intelectualización del hombre a la vez que enriquece permanente y creativamente lo logra.

2) El uso preferencial que recibió el castellano emplazó definitivamente a todas las lenguas amazónicas y andinas a un estado cada vez reducidas y minorizadas, condenándolas a funciones sociales secundarias y sin posibilidades de vehiculizar la cultura y como simples lenguas nativas e incivilizadas. Sus meras condiciones de oralidad y periferia social no son ninguna garantía para la subsistencia de éstas.

3) El hombre se halla comprometido con la lengua y por tanto es una obligación suya asumir su defensa contra la tirantez absorbente de la forma oficial. La escritura es la unica posibilidad para mantener su uniformidad y creatividad. Además este modelo está basado en simbolos superpuestos a la forma oral por tanto la escritura es una superestructura; que facilita el desarrollo creciente de la cultura y con ella la libertad.

4) La practica escritural requiere de una nomalización para su uso, la normalización uniformiza el uso correcto de las normas internas de la lengua, en esto consiste la ortografta y el buen uso sintáctico. La normalización debe ser ciclica para no caer en desfase con las formas orales correspondientes. La dinámica oral debe ser reconocida por la forma escrita, ésta registra y controla los cambios que muchas veces no son reglares. 


\section{BIBLIOGRAFÍA}

CHÁVEZ REYES, Amancio. Normalización del quechua, 1989. Huaraz, UNASAM, 1994.

"Lenguaje y política", en revista Ciencia, Tecnologia y Humanidades, UNASAM, Huaraz.

Aspectos formales de la palabra castellana. Lima, Fondo Editorial de la Universidad Nacional Mayor de San Marcos, 1998.

FASOLD, Ralph. La sociolingüistica de la sociedad.

GARVIN, Paul y Yolanda LASTRA. Antologia de estudios de etnolingüistica y sociolingiuistica. México, UNAM, 1974.

LABOR, William. Modelos sociolingüisticos. Madrid, Cátedra, 1983.

MARIN MARCOS, Francisco y Jesús SȦNCHEZ LOBATO. Lingüistica aplicada. Madrid, Ed. Sintesis, 2001.

TARELlo, Fernando. A Pesquisa Sociolinguistica. $2^{\mathrm{a}}$. ed. Sao Paulo, 1986.

\section{Biblioteca de Letras}

TORSTEN, Husén y Susán_OPPER Educaciónemulicultural y multilingüe. Narcea Ediciones, 1983.

ZÚÑIGA, Madeleine. y otros. Educación bilingüe intercultural. Lima, Fomciencias, 1991. 